\title{
Musical adventures in Antarctica
}

\author{
Alice Giles ${ }^{1}$
}

Music starts with Silence - it comes out of silence and goes back into it.

Silence is a very tempting concept for a musician - the equivalent of a blank canvas. It is the starting point for questions and for answers, and there are indeed many questions:

Why discuss sound and music in relation to Antarctica? Why take music there to perform? What kind of music is relevant? Who should be writing it? Even revisiting the 20th-century musical question, where does sound become music, or are they the same? Is music important? Where are the Australian compositions relating to Antarctica? Is it really silent there?

In early 2011 I travelled to Antarctica to give a concert. Every concert involves a level of exploration, a sense of journey, adventure, discovery; but this was the most extreme take on that concept in my career.

The purpose of my trip, as an Australian Antarctic Division Arts Fellow, was to present a concert at Australia's Mawson Station to commemorate the centenary of the Australasian Antarctic Expedition of 1911-14, my specific interest being to celebrate the participation in that voyage of my grandfather Cecil Thomas Madigan as meteorologist. The concert comprised words from Madigan's diaries, songs, hymns, and music he mentions in the diaries, and music by contemporary Australian composers especially written for the occasion. ${ }^{2}$

Madigan recorded in his diary the various hymns that kept his spirit going and the gramophone records that brought him cheer, clearly describing how live and recorded music was an essential component in maintaining equilibrium and the thread with home.

This was the thread that kept me going while preparing my trip, during my voyage and on my return. It was the concept that enabled me to relate to my voyage in a way that was natural to me professionally - something that was related to feeling, sensibility - something with a heart. I was able to accomplish this part on the continent, and develop it further in the concert presented at ANU School of Music. ${ }^{3}$

1 Ms Alice Giles, Director, Harp Centre Australia, PO Box 685, Yass, NSW 2582, alice.giles@sydney.edu.au.

2 Concert performed in the Red Shed, Mawson Station, Antarctica, 28 February 2011.

3 Live-streamed public performance of 'Alice in Antarctica' on 26 June 2011, Llewellyn Hall, School of Music, The Australian National University. 
And yet surrounding this the questions remain, the philosophical ideas that I had not confronted before.

Every continent needs its own individual musical expression - this starts with observation of the natural sound world and then starts to be transformed into an expression of the inner world or emotional response to the essence, rhythms and history of the continent. Such an expression is necessary for a natural cultural understanding of a continent, and especially important for Antarctica because so few of us humans are living there for any length of time - we are distant and need translators to give us the emotional understanding, the whole picture - something best possible through the abstract medium of music.

How are we to gain this musical translation? A musical interpretation of a place will always be a complex matter, involving responses to the emotional and visual landscape, the elemental forces in place (be they magnetic, atmospheric or weather conditions), local sounds in context, or the social and historical environment. Every season in Antarctica should have its musician, and composers should be actively sought out to assist us in understanding this vast continent. Every composer has a different way of hearing and expressing things musically, depending on their personality and focus. To gain a wide view we need many composers spending time in Antarctica.

Why perform music in Antarctica? Most interaction with Antarctica involves bringing things back - ideas, images, scientific information. Performing there involves taking something to the continent and letting the environment accept and shape the experience. It acknowledges the fact that we have established and are continuing a human social environment there, which has moved a step beyond the exploratory Heroic Age and demands a greater subtlety of interaction. It acknowledges the fact that we are there as human civilisation.

Performers engage with people and facilitate action - they are the alchemists to bring an emotion alive. My Antarctic voyage will always resonate in the vibration of my sound, but I see my contribution mostly as a facilitator, as someone who can try and stimulate interest and engage imagination.

The harp is a powerful mythical symbol, and the idea of a harp in Antarctica has stimulated people's imagination in a way that indicates there is a need for this kind of narrative to be happening.

The response to the video clip of my playing the harp on Davis Beach posted on my blog ${ }^{4}$ was very strong - beyond the actual musical content, the combination of the visual element of the harp on the beach, the sounds of the slushy ice combined with the simple composition, and the elephant seals in the background,

4 Improvisation on Davis Beach, February 2011 - elephant seals. 
drew in many people. Perhaps this is an illustration of how performances in Antarctica can help bridge that gulf of imagination and understanding - by combining visual and sound elements in situ while performing composed works or improvisations in Antarctica.

One of the improvisations I made was on the West Arm at Mawson - very simple, soft, because it was starting to snow and expressing a sense of the slowness of time. ${ }^{5}$

On a metaphysical level: I play the harp; I do this because the harp has strings which allow me to explore within, and express to others an infinite subtlety and range of emotions and refinements of feeling. The instrument has become an extension of myself. I took my harp to Antarctica and let the natural forces take over the production of its sound. This was as though the wind, the voice of the continent, was vibrating through both harp and (by extension) me. The journey became a personal transformation, as I imagine it is for most Antarctic voyagers. Once transformed, one is forever changed and deepened. The harp, following my trip, will always have the voice of Antarctica within. ${ }^{6}$

In this musical context it is interesting to explore why time spent in Antarctica is transformative.

Firstly, our rhythm and sense of time is altered. This starts with the long sea voyage: the unpredictable rocking of the ocean rhythm, large waves and emotional wildness, the singularity of the uninterrupted horizon, the pulse of the engines drumming memories of the sounds of land from us. Then moving into the stillness of the Antarctic waters, with travel sometimes suspended in a timeless smoothness, at other times slowed by the incremental passage of icebreaking. On land the ancient ice and rock speak of a timeframe in millennia; there is a disruption of human-controlled rhythms - day and night rhythms are changed, and working patterns are unpredictably ruled by the larger weather patterns. The focus on science - the upper atmosphere with the magnetic spectrometer, the geophysical sciences - is all related to subtle subatomic and larger tectonic rhythms.

Composers could start grappling with these more abstract concepts of time/ rhythm/patterns and translating them to a new expression.

Secondly, the whole world around you in Antarctica is uncluttered, which is a profoundly important lesson. There is a paring away of non-essentials, both in the natural world and in social or professional obligations, leaving one free to see the essence of things more clearly for a time. This focus has increased my

5 Improvisation West Arm, Mawson Station, March 2011.

6 Wind harp, Davis Station, February 2011. 
ability to appreciate the beauty of nature in my everyday life; more than an appreciation, it is a refinement of love in response to the natural world. The sky over Yass will always touch me more intensely now with its colours, blue and white, tinged with sunset hues, changing but the same, as a reminder of my responses to that southern icy world.

Issues that are not much discussed today, as we don't have the language for it; maybe that is why we have music ...

Thirdly, there is an intangible intensity about the Antarctic experience that is experienced by many, but few could articulate this as well as a fellow traveller on the Australian Antarctica Division's voyage 3 for 2010-11, a scientist who had spent various periods of time there. He said he experienced greater extremes of emotions while there, and really had to gauge his behaviour differently to accommodate this change. There can be many reasons for this, to do with the different social environment, the different circadian cycles, the different magnetic forces and other natural environmental influences as yet undiscovered. The point I would like to make is that the integration of these influences is fascinating and important on a human level, and deserves translation into music by composers interested in exploring the complexities and subtleties of the emotional and natural worlds.

Once I had left the continent, back on the ship I tried to think of what I would wish to write if I could compose something for myself, and my overriding impression after my Mawson Station visit was an extremely deep vibration to reflect the all-pervasive power of the rocks - powerful bass notes in an unconventional tuning and scale, rather like the fundamentals in an overtone singing chant. This overlaid with high repeated patterns with which to reflect the sparkling brightness, the ancient patterns of the ice - again very similar to the concept of overtone chanting. I made a sketchy and unsatisfactory - for me - attempt to realise this personal response, which I will possibly develop later into a more satisfactory composition. I mention it only to illustrate that this would not have been my musical/emotional response if I had only looked at visual images of Antarctica.

A wider question now occurs to me. We have a large number of Australians who are funded to go to Antarctica (by various government, private and other organisations), but only a very few funded places selected from the humanities. I am now imagining a society which would firstly send many musicians, visual artists, and historians to the unknown continent, with funding for a few scientists each year — possibly a biologist and a LIDAR scientist ${ }^{7}$ this year, a magnetic spectrometer researcher and geologist the next. Not necessarily more

7 LIDAR (light + radar $)$ is a remote sensing technique for measuring distance with the use of lasers. 
or less sensible - just a different perspective. (In fact scientists and performing artists are different sides of the same coin, and have more in common than other disciplines: focus, intellectual imagination, personal discipline, and practical ability.)

But this leads me to the further question: is music the cause or the result in our civilisation? You may think this a ridiculous question, but the ancient Chinese saw the keeping of particular scales as being essential for the preservation of their culture. If the pitch or modality of the scale changed, the dynasty changed as a consequence. Our musical explorations may or may not be as important as other explorations. Certainly, to be human is to feel and to express a huge range of subtle responses to the outside world - natural and social.

But then I return to the question (more questions!) — where are the Australian composers interested in writing music about Antarctica? One hundred years after Dr Madigan listened to the gramophone and sang the songs he brought with him, there remains very little music written by Australian composers that directly relates to Antarctica, even though Australians have been a consistent presence on the continent all that time. Are they waiting for commissions is this the Australian culture of composition? Is it a reflection of the lack of cultural connection with Antarctica over the last 100 years? And why am I the one asking these questions besides Rupert Summerson? ${ }^{8}$ Have other people noticed that there is a silence here? Why are other countries so much more ahead of us in musical expressions of Antarctica? So many more New Zealand composers are being 'tapped on the shoulder' to go and interpret the place.

I hope my arts fellowship and my voyage to Antarctica can be a starting point for many other Australians and especially composers to start asking these questions. Because if we would like an Australian public that is passionate about what happens in Antarctica, we need to know how to engage hearts and minds powerfully: music has this power.

8 See Rupert Summerson's paper 'On a Vast Scale' in this volume, from his presentation at the 'Antarctica and Music' conference in 2011. 
This text is taken from Antarctica: Music, sounds and cultural connections, edited by Bernadette Hince, Rupert Summerson and Arnan Wiesel, published 2015 by ANU Press, The Australian National University, Canberra, Australia. 